\title{
Developing a TRL-oriented roadmap for the adoption of biocomposite materials in the construction industry
}

\author{
(C) Higher Education Press 2021
}

\begin{abstract}
The construction industry is a major contributor to environmental pollution. The effect of the construction industry on the environment may be mitigated using eco-friendly construction materials, such as biocomposites. Once developed, biocomposites may offer a viable alternative to the current materials in use. However, biocomposites are lagging in terms of adoption and eventual use in the construction industry. This article provides insights into the steps for biocomposites to become a product that is ready to use by the construction industry in a structural role. The development and the adoption of such a material is tackled with the use of two concepts, i.e., technology readiness level and roadmapping, and explored in a case study on the "liquid wood". Furthermore, interviews in the construction industry are carried out to identify the industry's take on biocomposites. A customized roadmap, which underlines a mostly nontechnical perspective concerning this material, has emerged. Additionally, the adoption and diffusion issues that the "liquid wood" may encounter are outlined and complemented with further recommendations.
\end{abstract}

Keywords biocomposite, technology readiness level, roadmap, interview, "liquid wood"

Received May 29, 2020; accepted January 14, 2021

Tudor-Cristian PETRESCU ( $₫)$

Department of Structural Mechanics, Faculty of Civil Engineering and Building Services, Gheorghe Asachi Technical University of Iasi, 700050 Iasi, Romania

E-mail: tudor.petrescu@tuiasi.ro

Johannes T. VOORDIJK

Department of Civil Engineering, Faculty of Engineering Technology, University of Twente, 7552 LW Enschede, the Netherlands

Petru MIHAI

Department of Concrete, Materials, Technology and Management, Faculty of Civil Engineering and Building Services, Gheorghe Asachi Technical University of Iasi, 700050 Iasi, Romania

\section{Introduction}

The construction industry is a major source of pollution. Construction sites can generate pollution through its specific activities and materials. Particulate matter (especially $\mathrm{PM}_{10}$ ), asbestos, nitrous oxides, and other contaminants are released into the air and can travel long distances (Environmental Pollution Centers, 2017). Compounding these problems is the fact that the construction industry does not use environmentally friendly and sustainable products except wood and stone to some extent. Nowadays, concrete and brickwork, the most popular building materials, take up large amounts of energy (often fossil fuel) to be created (Ortiz et al., 2009).

The effect of the construction industry on the environment can be mitigated using new environmentally friendly construction materials, i.e., made from natural renewable resources and should be biodegradable to a certain degree (John and Thomas, 2008). Biocomposites are studied for some time now, and their potential applications (Faruk et al., 2012) in toys, musical instruments, furniture, and door and floor finishing, are recognized (Nägele et al., 2004; Tecnaro GmbH, 2020).

The adoption and the eventual use of biocomposites in the construction industry are lagging unlike in other economic branches. Structural applications are few, far between, and arguably the most important characteristics in the building industry. However, to this day, relatively few structural applications are developed with an eye towards biocomposites (Eindhoven, 2016; Vos, 2018). Thus, the accelerated development and deployment of biocomposites are needed. As such, the central research question has emerged: What steps should be taken for biocomposites to become a ready-to-use product by the construction industry in a structural role?

Several roadmaps exist for products or processes that need to pass through several developmental stages. For example, Rödel et al. (2009) propose a roadmap for the development of advanced ceramics and their associated products in the future. Siebelink (2013) has developed a 
business roadmap for construction companies to focus on innovation efforts. Lee et al. (2013) propose a service device technology roadmap for the smart city development.

However, authors cannot identify any roadmap specifically tied to the use of biocomposites in the construction industry as a rehabilitation solution. Authors consider this as the core research gap.

In other words, the manufacturer of the said biocomposites may have an internal roadmap to illustrate the "steps" that the biocomposite material takes from design to production, and a roadmap illustrating how the biocomposite should be used in a certain field is not available. Consequently, biocomposites can be viewed as a product but "requires" a roadmap that can illustrate their usage in the context of the construction industry. This lack of information is addressed in this paper.

Two concepts, i.e., the technology readiness level (TRL) and roadmapping, are used to answer the abovementioned question. The TRL is a good control tool for "tracking" the development of a product by following certain "steps". The roadmapping is a useful technique to plan the proposed development "path" of a product and note important decisions, consequences, and effects to reach a certain goal. Both concepts are used to conduct a case study on a single product of the biocomposite class of materials, i.e., the "liquid wood".

This article is organized as follows. In Section 2, the concepts necessary to answer the research question stated in the introduction, i.e., TRL and roadmapping, are introduced. Section 3 explains the design of a TRLoriented roadmap, which should indicate the "path" that the "liquid wood" needs to take to become a ready-to-use product by the construction industry. Section 4 explains the application of the roadmap for the specific situation of the "liquid wood" on the basis of construction industry interviews and by considering challenges and decisions at precise developmental stages. Section 5 debates the obtained results. Section 6 concludes the article and summarizes the research limitations and further research directions.

\section{Theoretical framework}

Two concepts, i.e., TRL and roadmapping, are proposed. These concepts are hoped to illustrate the "path" that the biocomposite material should "follow" to become ready for use by the construction industry.

\subsection{TRL concept}

The TRL concept has recently become widely used, but its roots can be traced back to around 1969 when the US National Aeronautics and Space Administration (NASA) is looking for a tool to map the development of future technology. A "technology readiness review" is suggested to decide whether a certain technology is ready for use in a project (Mankins, 2009). This concept is not initially accepted by NASA, but the idea has persisted. In 1989, the "readiness level" concept is finally published (Sadin et al., 1989) as a new technology development strategy for NASA. The 1986 Challenger space disaster has promoted this change. In 1999, the US Department of Defense needs a tool to track which military technologies should money be spent on, and a version of the TRL is eventually used (Schinasi, 1999). Eventually, after passing through the European Space Agency (ESA, 2008) as another means of tracking technological development, TRL is adopted by the European Union (EU) as a policy tool to promote innovation in the context of EU-funded projects in various fields (NASA, 2014).

The TRL scale is basically a 9-level scale (Table 1), which attempts to describe the steps through which a technology must pass. This scale starts from a conceptual idea to a final ready-to-use product.

Table 1 Technology readiness levels (Mihály, 2017)

\begin{tabular}{ll}
\hline Technology readiness levels \\
\hline TRL 1 & Basic principles observed \\
TRL 2 & Technology concept formulated \\
TRL 3 & Experimental proof of concept \\
TRL 4 & Technology validated in a laboratory \\
TRL 5 & Technology validated in a relevant environment \\
TRL 6 & Technology demonstrated in a relevant environment \\
TRL 7 & System prototype demonstration in an operational environment \\
TRL 8 & System completed and qualified \\
TRL 9 & Actual system proven in an operational environment \\
\hline
\end{tabular}

Overall, the TRL can be used in a wide array of industries and activity fields, can easily be adapted for use in various contexts, and is generally easy to follow and understand.

\subsection{Roadmapping concept}

The US automotive industry has created the roadmapping to make improved decisions in the long term and manage future investments. This method is initially labeled as technology roadmapping and has gained publicity through its application in the field of telecommunication by firms like Motorola (Probert and Radnor, 2016) and Philips (Groenveld, 1997).

A roadmap provides a structured and often graphical means to explore and communicate the relationships between evolving and developing markets, products, and technologies over time (Phaal et al., 2004a). Roadmaps are used for some time now (Motorola's roadmaps being a "classic" example of roadmapping in strategic planning) and have gained popularity and acceptance throughout 
many industrial branches (Willyard and McClees, 1987). Nowadays, the concept is used in a variety of industries with an equally broad spectrum of applications, e.g., marketing, technology development, product development, forecasting, and strategic planning.

A good roadmap should be designed to answer three main questions: "Where do we want to go?", "Where are we now?", and "How can we get there?" (Phaal and Muller, 2009). If these questions can be truthfully and realistically answered, then the chance that the emerging roadmap will help in managing future events, decisions, and uncertainties in the development of a new product/ strategy/service/technology is good.

Besides answering these questions, which would form the "information structure" part of the roadmap, the "graphical style" should be mentioned (Phaal and Muller, 2009). Roadmaps, being often graphical in nature, should use one of several possible formats, colors, and highlighting tools. As an example, Phaal et al. (2004b) offer a good classification of roadmaps, which are complete with graphical models.

Phaal et al. (2003) argue that the customization is important for roadmapping because each application subjected to roadmapping is different and depends on its specific needs, focus area, and context. "Good" or "bad" roadmaps do not exist. Roadmaps are created for a specific purpose. Thus, the act of building a roadmap can be modified in terms of process, content, structure, and timing. Once the roadmap is done, future challenges are keeping the roadmap alive and prepared for rollout. Keeping the roadmap alive entails updating the roadmap with the latest changes and developments. This activity should be done as events pertaining to the evolution of the roadmap unfold in time. The initial roadmap is not the final version and should be disseminated, updated, improved, and studied whenever necessary. The rollout means that the roadmap should be adopted in other parts of the organization (Phaal et al., 2004b). In the case of the "liquid wood", the roadmap should be adopted by parties working on the project through communication and dissemination.

\subsection{Bringing the concepts together: TRL-oriented roadmaps}

The abovementioned concepts should be crystallized in a "usable" form. One way to achieve the desired form is through the use of TRL-oriented roadmaps. The available literature provides some interesting examples and discussion about TRL roadmaps in various industry fields.

The first example is the graphic TRL roadmap on the development of NASA's advanced chemical and nonchemical propulsion systems for the future by Palaszewski et al. (2010). The development is correlated with TRL levels and a timescale. The roadmap may look complicated but is a good representation of the TRL levels at least in the way NASA, the creator of the TRL concept, uses them.
The second example is the technology TRL roadmap on the development of heat exchangers in power plants by Sabharwall et al. (2012). Interestingly, this article displays condensed and expanded versions of the roadmap, which are graphical and illustrates that a TRL roadmap is a flexible tool that can be used in a myriad of ways. Again, the necessary steps are correlated with respective TRL levels.

Finally, Ruehl and Bull (2012) provide a TRL roadmap with graphic representation in the case of the Wave Energy Converter (WEC, basically sea wave shore energy harvesting) technology. Additionally, a roadmap for the development of the WEC Farm (the product/device through which wave energy is harvested for later use) is presented. The TRL scale is used in almost the same way as a timeline on a "regular" roadmap, thereby helping track the project through some defined stages, i.e., from inception to eventual commercialization.

In summary, TRL-oriented roadmaps combine the "best of both worlds". Roadmaps combine their graphical and concise character in highlighting important information and developmental steps. The TRL scale is used to track the progress of a particular issue/item/product in a way akin to a time scale.

\section{Methodology}

Previous subsections discuss the concepts of roadmaps and TRL and show that they can be "fused" together. In the following subsections, the focus will shift towards describing the methodology of designing a TRL-oriented roadmap for biocomposite materials. Biocomposites represent a broad category of products (Faruk et al., 2012). As such, the following TRL roadmap methodology and subsequent case study will revolve around a single product from the biocomposite class, i.e., the "liquid wood".

\section{1 "Liquid wood"}

The "liquid wood" is a polymeric biocomposite with a matrix made of lignin and other constituents, e.g., mostly organic fibers. Thus, from a material structure point of view, this material can be viewed as a representative of most of the known biocomposites. The "liquid wood" is available in three presentation forms, namely, Arboform, Arbofill, and Arboblend. Each form contains varying lignin contents, but all forms are environmentally friendly and biodegradable to some degree (Nägele et al., 2014). The "polymeric" aspect of the "liquid wood" indicates that it can be processed in the same way as thermoplastics (i.e., using injection molding, extrusion, and hot drawing). This feature may be viewed as a departure from how composites and biocomposites are generally applied but may represent an advantage for some types of applications (e.g., various 
items can be obtained relatively easy from this material by using extant injection machines). The various tests performed on the material (Nedelcu et al., 2012; 2013; 2014; Puiu et al., 2017) seem to point out that the "liquid wood" can be used in a structural role in the construction industry. To this point, however, little attempt has been made to use this material in a structurally relevant manner (in buildings), and research is confined to a laboratory environment and some isolated projects.

\subsection{Proposed method}

A possible method for developing a roadmap, i.e., the T-Plan Fast Start Process, has been put forward by Phaal et al. (2003). This method is intended for a quick and effective start of the roadmap development within a company. The "standard" process is intended for product planning within a business organization and offers flexibility in terms of scope, aim, timeframe, available information, and unit of analysis.

The resulting roadmap should contain the three major "pillars" of any generic roadmap architecture: Product (delivery/"know-what"), technology (resources/“knowhow"), and market (purpose/“know-why”) (Phaal et al., 2004a). Overall, this method is quite comprehensive in its scope, easy to grasp by entities that have little or no experience with roadmapping, and represents a good "practical" introduction in this field.

From the multitude of principles governing the Fast Start Process, the most important principle related to the "liquid wood" project is the development of a "first-cut" roadmap. This approach, towards a "rough" but practical roadmap, is selected as a keystone to be followed when creating the "liquid wood" TRL-oriented roadmap because such a roadmap should be positioned in a sectoral level, which is in contrast with the company-level T-Plan Fast Start Process.

Moreover, the T-Plan Fast Start Process requires some basic adaptations. Instead of the workshops found in the original description of the process, regular meetings on the three basic pillars of the roadmap are held with project teams. First, product and technological aspects are discussed. Marketing aspects are left at the end because the product should be ready for use before presentation to potential adopters.

The starting point for the T-Plan Fast Start Process is represented by the "product pillar". The "product pillar" aims to acquire product data or characteristics that help determine its suitability for use in the construction industry. Such data are collected after various tests, and computer simulations are performed. Furthermore, in this stage, the "liquid wood" is introduced to the product research team in the laboratory. The already known data about the product (i.e., the so-called "state-of-the-art" of product given, in terms of available information, by previous research and the manufacturer's data sheets) are shown and disseminated. Further research is required to obtain information about "liquid wood". As an example, the core characteristics (such as composition, biodegradability rate, and acid/base/ultraviolet radiation (UV) attack resistance) of construction materials (such as traction, bending, and compression) should be known before attempting structural testing. The material should be good enough to be regarded as suitable for possible construction use. The final aim of the product and the TRLoriented roadmap is discussed together with its expected use. Once most of the tests are performed, an indication of possible use in the construction industry can usually be obtained from the test results.

The "technology pillar" tackles the subject of how the "liquid wood" is used on the construction site in a practical sense (which is in accordance with the product's expected use or aim) and achieves the said objective. Here, the product is passed over to the technology development team. However, until the product reaches the construction site, increased material testing should be performed. Necessary tests and associated testing methods are put forward. In this stage, these tests are twofold in their nature. On the one hand, the tool/device required for the use of "liquid wood" is studied/developed. On the other hand, the interaction between the "liquid wood" and wooden structures is determined. The collection, processing, and dissemination of obtained data contribute towards the development of a complete technical solution (i.e., a portable adaptation of thermal injection technology), which is suitable for the "liquid wood" when used as a structural rehabilitation material.

Finally, defining the "market pillar" consists of gathering external input about the "liquid wood". In general, some forms of "outside" input for roadmaps, i.e., external (from stakeholders and other vested parties) or internal (from other departments in an organization), are expected (Garcia and Bray, 1997; Petrick and Echols, 2004). For any new construction material seeking enter the construction industry market, the adoption and the diffusion assessment that seeks to gauge if the product will be met with any success (and to what degree) is a must. Potential opportunities and barriers in terms of market/sector adoption should be identified and evaluated.

\subsection{Data collection method/interview}

In the case of the "liquid wood", an empirical method for obtaining the external input is used. Specifically, a series of interviews in the construction industry, with structured questions following the principles set out by the Rogers Diffusion Model (Rogers, 2003), is conducted.

The interviews are carried out using a semistructured questionnaire. All answers are audio recorded to help in subsequent processing with the expressed knowledge and agreement of interviewees to write this article. For privacy reasons, their names and affiliations are not made public. 
Fifteen interviewees who have different specializations in the field of the construction industry are selected. The selection criteria for the interviewees are few but clear. The interviewee should:

- be from the construction industry and have ideally worked their entire career in civil engineering,

- still be active in the construction industry, and

- have diverse qualifications to obtain relevant answers across the various industry fields.

The "snowball sampling" within the previously mentioned sampling frame is used to contact potential interviewees (Goodman, 1961). This sampling is a smooth process because the practice of recommending contacts in the construction industry is established in accordance with the interviewees.

Considering all these criteria, the "candidate pool" is as follows. From the point of view of their professional training (university-level education), 12 civil engineers and 3 architects are interviewed. Breaking these numbers further into expertise categories, out of the 12 civil engineers: 1 is a researcher studying heat-resisting building materials, 1 is in occupational health and safety, 4 are structural designers, and 6 are site engineers specializing in building execution. Moreover, eight interviewees lead their own construction companies, have activities related to their areas of expertise, and do construction-related consultancy work. The age range is between 35 and 65 years old to cover the "older" and "younger" generations of specialists. All interviewees are still active in their fields.

The intention is to gauge how the construction industry perceives biocomposites and particularly if the "liquid wood" has any future and related uses. The said intention doubled as an attempt to identify early adopters. Consequently, the industry branches to which this product may be marketed to in the future. Any flaw or gap in product performance or other aspects may be usefully pointed out by these outside parties. Overall, the feedback, when presented with this new product, is important to the future of "liquid wood".

\subsection{Fast Start Process adapted for the "liquid wood"}

Given these considerations, the Fast Start Process on the development of the "liquid wood" is adopted in this study in the following manner (Fig. 1).

The T-Process is presented in a customized form, which is suited for the "liquid wood" case.

The last step in the T-Plan Fast Start Process is the actual building of the roadmap. Thus, the progress of the development of the stages of "liquid wood" may be represented in terms of a correlation between the timescale and the TRL progression on the roadmap. Hence, a clear model to depict this correlation is the "XOY" axis model. The horizontal axis " $O X$ " represents the timeline, and the vertical axis " $O Y$ " represents the TRL levels. The origin " $O$ " is represented by the TRL level 4, where the "liquid wood" is situated when this article has been written. The round circles contain the definitions of the TRL levels, which culminate with the end goal in a concentric circle - TRL level 9. Moreover, decisions and tasks are linked and represented accordingly. A "how-to" of the roadmap, which has the role of a "roadmap user manual" (i.e., how the roadmap should be read and used, see Section 4.1), is also prepared.

As a final remark, the roadmap is split into three layers, i.e., market, technology, and product. This process of partitioning the roadmap helps in underlining the evolution of the "liquid wood" and the roadmap and giving a clear indication as to where the three "pillars" of roadmapping are found.

This paper focuses towards the novel application of the two previously mentioned concepts. These concepts are not new but form the "lens" through which one must "look" to "visualize" the research perspective. Charting the development process of the "liquid wood" from a semiexperimental material into a complete rehabilitation

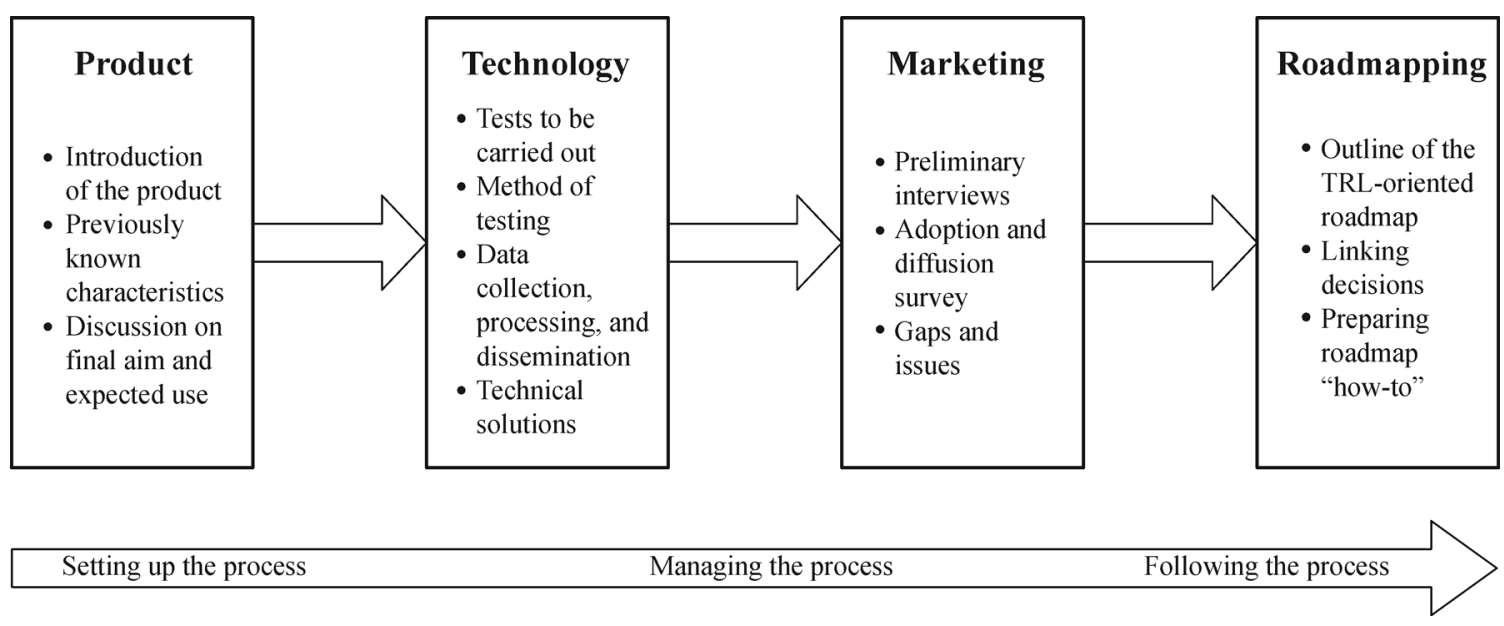

Fig. 1 Fast Start Process of roadmapping (based on Phaal et al. (2003)). 
solution for use in the construction industry is straightforward through the use of TRL and roadmapping. Furthermore, these concepts help immensely because the three "pillars" tackle distinctive but complementary aspects of the development of the "liquid wood". The "product pillar" is concerned with the "liquid wood" material research and its properties. Then, the "technology pillar" is involved in the elaboration of the usage procedure and tool for "liquid wood". Finally, the "market pillar" represents the perspective shift from product/technology to market-oriented. Correspondingly, this change in the roadmap from a product/technology level to a sectoral level is backed up by a product adoption and diffusion study. For all three "pillars", the TRL levels lead the progress incrementally, and the roadmapping is used to express these events graphically.

\section{Results}

The roadmap, which results in following the application of the adapted T-Plan Fast Start Process, can be viewed in Fig. 2.
The progress of the "liquid wood" through various TRL stages is represented by connecting arrows, and on the said arrows, the activities needed to increase TRL levels are briefly listed. The first pair of rectangles ("liquid wood" nanoparticles vs. "liquid wood" pellets) represents a purely technical decision. Similarly, the other rectangle (the adoption and diffusion survey) represents an attempt to obtain some external feedback regarding the use of "liquid wood" in the construction industry. The decision and the survey are linked with dashed dots to their respective timeline and solid arrows to where their input comes into play. The decision and survey are not, however, linked to TRL levels because they do not exert an immediate influence upon the overall progress of the material. The three solid arrows in the bottom left that go towards TRL level 4 should be treated as past input that enables the TRL level 4 to be reached.

Given that the "liquid wood" spends most of the time in laboratory development up to and including TRL level 5, the focus is towards the product and its characteristics, resulting in the "Product" label on the bottom layer. Between TRL level 5 and up to and including TRL level 7, the product leaves the pure laboratory stage and is used in

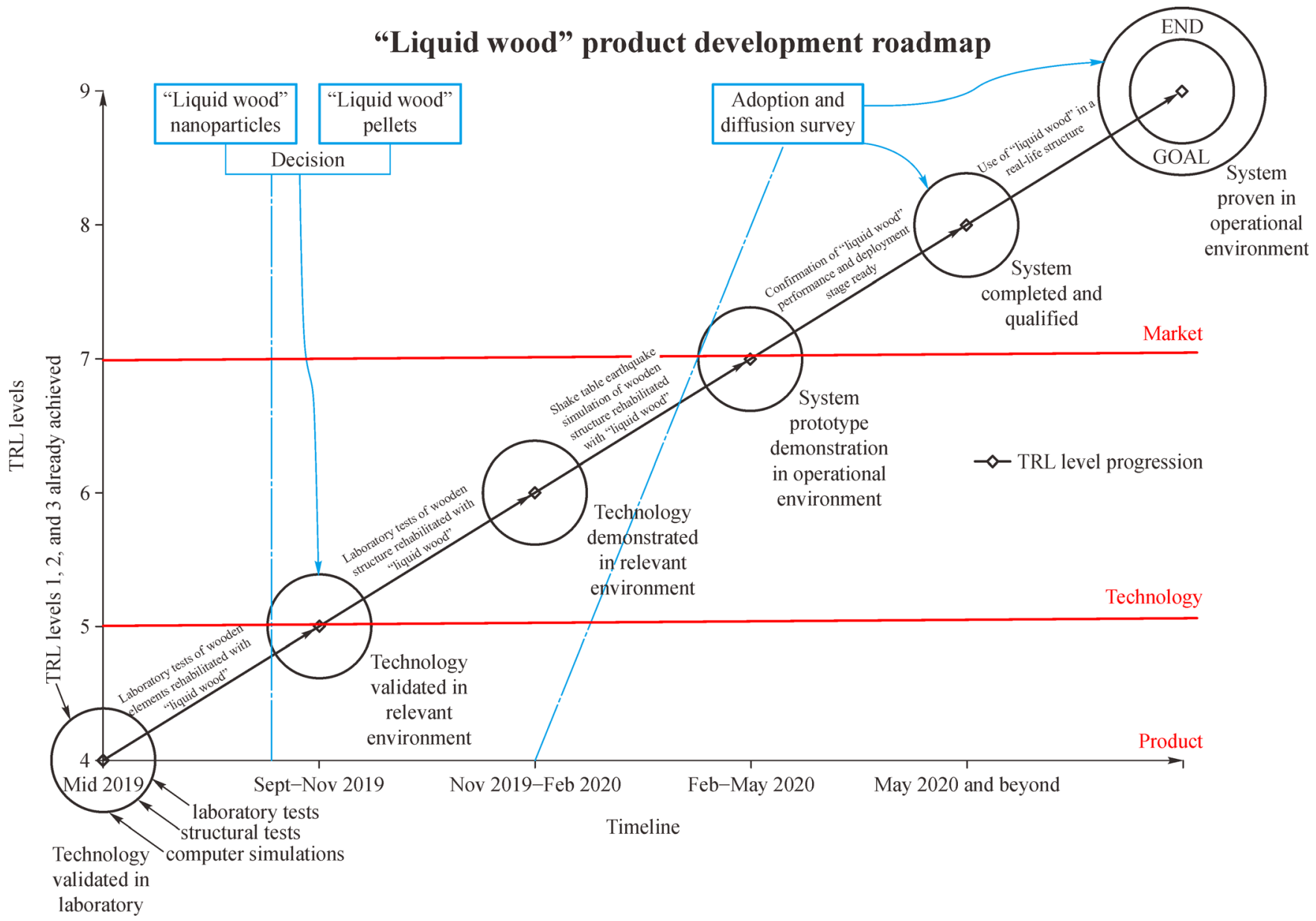

Fig. 2 "Liquid wood" TRL-oriented roadmap. 
conjunction with regular wood (even if it is still in controlled testing conditions) to validate its properties. In the middle layer, the label "Technology" is used because the injection technology necessary to subsequently use the "liquid wood" on the construction site is tried and validated. From the TRL level 7 and above, the "liquid wood" is theoretically ready for use by the construction industry as a rehabilitation solution consisting of product and use technology.

The following subsections explain the "how-to" aspects regarding the proposed "liquid wood" product roadmap. Said subsections encompass the necessary steps to progress through the TRL levels. The "how-to", corresponding to the reach of each TRL level, is explained from the TRL level 4, which is used as the "starting point" for the roadmap. All explanations corresponding to TRL levels are listed in terms of product, technology, and market "pillars".

\section{1 "Product pillar"}

- TRL level 4-Technology validated in a laboratory

The TRL level 4 is the starting point of the roadmap. In other words, the "liquid wood" as a material fit for the structural rehabilitation of buildings initially sits on the level 4 . The product is validated in the laboratory through the completion of three distinct activities (which may be considered as previous input data on the achievement of the TRL level 4), i.e., laboratory tests, computer simulations, and structural tests. Laboratory tests allow a thorough characterization of the material and the discovery of all properties. Once laboratory tests are completed, computer simulations allow the material to be "tested" before the actual structural testing. Structural tests prove that the material exhibits a satisfactory bearing capacity (i.e., is able to take overloads). Overall, these tests confirm the suitability of the "liquid wood" for use in the construction industry and point out some possible applications.

\section{2 "Technology pillar"}

Before the "liquid wood" starts the necessary activity to get into TRL level 5 but after completing TRL level 4 activities, a purely technical decision on the use of the "liquid wood" should be made. The choice is basically between two presentation forms of the material (pellets vs. nanoparticles) and relates exclusively on which one of the two is more suitable for workability in construction site conditions. Regardless of the method that will be selected, the progression towards TRL level 5 and the end goal is the same.

- TRL level 5-Technology validated in a relevant environment

In TRL level 5, the activity to be carried out is laboratory testing (i.e., structural testing) on wooden elements and "rehabilitation" (i.e., injection) with the "liquid wood". The core idea is to use and study the behavior and the synergy of the two materials subsequently. The "liquid wood" shows that it does not fail before the wooden part of the structural element. This confirms its suitability for construction use. Once the tests are successfully completed, the TRL level 5 is considered achieved.

- TRL level 6-Technology demonstrated in a relevant environment

The next step is to test the integrity of a damaged wooden structure, such as a simple (e.g., square-shaped) ground floor-only house, that is rehabilitated with the "liquid wood". Given that rehabilitated wooden elements are structurally tested, the stage testing on the impact resistance and the fire resistance is performed, and the overall integrity and the robustness of the structure are observed. Here, the "liquid wood" does not negatively affect the integrity and the robustness of the structure. By contrast, following the fire resistance testing, the "liquid wood" shows that it burns layer by layer and have a predictable and safe behavior. Once the tests are successfully completed, then TRL level 6 is considered achieved.

- TRL level 7-System prototype demonstration in an operational environment

The next step is to perform dynamic tests on a wooden structure rehabilitated with "liquid wood", which has a structure similar to that mentioned in TRL level 6. In the construction industry, the ultimate test for a structure is an earthquake. The structure is installed on a shake table. When started, particularly destructive earthquakes around the world (Vrancea 1977 (Purcaru, 1979), San Francisco 1986 (Sykes and Jaumé, 1990), Sumatra 2004 (Lay et al., 2005)) are "fed" as data to the shake table. Following the "earthquakes", the building's structural response is generated and allows for the observation of certain relevant parameters, such as flexibility (or rigidity), response period, and damping ratio. The "liquid wood" preserves the dynamic characteristics of wooden elements, and its use for rehabilitation does not weaken the wooden structure.

\section{3 "Market pillar"}

Before the start of the activities of TRL levels 8 and 9, the adoption and diffusion survey is conducted, because valuable input data for the aforementioned activities is thus collected. Said survey is an attempt to gauge the construction industry's response when faced with an alternative to the classic and composite building materials used in rehabilitation, that is, "liquid wood", a biocomposite. Whether the construction industry is familiar with this new class of materials, any future perspective, and any willingness for use in future construction projects is explored.

- TRL level 8 - System completed and qualified

The next steps are the confirmation of the performance 
and the deployment readiness of the "liquid wood". These steps are theoretical in nature and involve the collection of all gathered relevant data, which are centralized and synthesized as the "product sheet" to obtain a condensed statement of the products' performance and method of use on the construction site, precautions, and hazards at deployment (i.e., a "liquid wood" user manual). The said documentation may form the basis of certification for use in the construction industry by relevant authorities, thereby achieving the qualification of the system. This step is described with the help of construction industry interviews.

Most interviewees (11 persons) are aware of the term "biocomposite". Out of the 11 interviewees, two know biocomposites. One interviewee, who specializes in wooden structures, uses boards and plates that the manufacturer describes as "biocomposite". The other interviewee works with biocomposites that make water filtration membranes in a sewage project. In both cases, the persons clearly state that these projects are quite unique and have a low chance of repeatability. The four people who have not heard of biocomposite materials have simply never came across the term. Nevertheless, all interviewees can easily guess that the term "biocomposite" refers to composite materials with some sort of "bio" component or aspect tied to them. Besides the two interviewees who are conservative in their views, all have some positive remarks about biocomposites. The consensus is that, if successful, such materials may replace classic ones, such as concrete, ceramic tiles, or bricks, to a certain degree, thereby lowering the pollution associated with their use. Thus, a small part of the Romanian construction industry has some (albeit limited) knowledge about biocomposites. Moreover, many interviewees can suggest alternative uses for the material aside from the one presented to them during the interviews. Specifically, nine interviewees suggest alternative uses. Two of the architects suggest that the "liquid wood" should be "pourable" like concrete before hardening to take various shapes or be used as an encasement material for various structures. The person active in research suggests that the immersion of the "liquid wood" (hardening underwater, like Roman concrete if possible) is a desirable property. The other interviewees propose versions of wall cladding (wall tiles), which can be made out of "liquid wood" (at least for aesthetic considerations), and possibilities of the "liquid wood" being sprayed on various surfaces (like shotcreting) to obtain a quick and effective encapsulation (may be structural) of assorted building elements.

Nevertheless, the actual use of biocomposites has not been correlated with the perceived optimism of the interviewees because examples of biocomposite material use in a structural role throughout the construction industry are infrequent.

- TRL level 9-Actual system proven in an operational environment
After achieving TRL level 8, the final step in the development of the roadmap is to deploy the "liquid wood" in a real life-sized structure. This step can be done either via a private investor interested in this technology or an EU-funded proposal that supports such pilot projects. A substantial amount of time may pass before this final activity is carried out, and this activity is expected to be completed somewhere in the near future.

In the interview results, most respondents point out how a new material spends years entangled in the bureaucracy associated with certifying such a product for the construction industry. 12 interviewees believe that the product certification is lengthy due to various reasons, such as bureaucratic laziness, conservatism in the industry, lack of open-mindedness on these types of materials, and the need for workforce and specialist's training for use. The three remaining persons express that the product certification should not take long. By contrast, the "bio" properties should help expedite the process. All interviewees believe that the "liquid wood" should go through this process as well. Four interviewees usefully point out an interesting case about novel materials trying to enter the Romanian construction market. Apparently, an often-cited example in various engineering circles is the drywall. The drywall technology has entered the Romanian construction market in the mid to late 1990 s but takes approximately 15 years to gain widespread acceptance and use (with full manufacturer support, training sessions, and workshops). The situation is suggested to improve nowadays but not by a considerable margin.

Finally, none of the interviewees like to carry the "early adopter" mantle. None of the answers is definite negation but rather conditional. Interviewees cite several reasons. First, most interviewees state that they are not willing to work with a material that the manufacturer does not provide product support (e.g., training sessions and product presentations). This finding correlates with the experience of the product's research team, which reports a bland experience with the Tecnaro $\mathrm{GmbH}$ in procuring the "liquid wood". Upon contacting the manufacturer, the members of the research team are simply instructed to contact the Romanian distributor of the "liquid wood" for procurement. Any additional question that the members of the research team have about the material has received no response. Second, extensive knowledge about the material should be made available. The Tecnaro $\mathrm{GmbH}$ only provides product data sheets (already available on their website) with ISO-compliant testing that is carried out while developing the "liquid wood" and some advertisement related to which domains the product is or can be used. The interviewees acknowledge that construction industry researchers should uncover most of the secrets that the "liquid wood" holds and indicate how suitable the "liquid wood" is for use in the construction industry and that the manufacturer and/or the distributor should be involved in providing relevant product data. Third, the 
price does not sit well with the interviewees. At current costs, the "liquid wood" is only suited for use in limited quantities for specific applications. Finally, interviewees have the consensus that the wide availability (either online or in stores) is important for the projected extensive use of such a product.

Dissecting all these answers, engineers, architects, and managers are dissatisfied with the amount of information that the Tecnaro $\mathrm{GmbH}$ and their distributors are making available for the "liquid wood" and are not willing to use or suggest the use of this material without sufficient data, resulting in aversion to being "early adopters". Price and availability seem to also aggravate these issues. The underlying layer to these conclusions is that a major barrier in the adoption and the diffusion of the "liquid wood" on the construction market can be identified. Without satisfactory manufacturer support, the adoption and the diffusion of "liquid wood" can be lengthy, because other parties (i.e., researchers) need to come up with sufficient and relevant data for the establishment of the usability of the product in a given industry.

\section{Discussion}

This article aims to present the construction and the application of a TRL-oriented roadmap on a specific class of biocomposite ("liquid wood") and apply this material in a structural role in the construction industry. Again, one should keep in mind that the TRL-oriented roadmap is already used in the research of the "liquid wood" because of its part in an ongoing research project.

\subsection{TRL and roadmap use}

First, the TRL for the "liquid wood" is a good tool for planning development. Supporting this finding, Clausing and Holmes (2010) argue that the TRL has a close relationship with the process or the product that is the subject of the TRL scale. Moreover, Cornford and Sarsfield (2004) believe that the TRL scale is well suited to a particular technology evaluation and point out that integration challenges may occur when a technology is used in novel applications (the example of technology included in space systems is analyzed). In the case of the "liquid wood", the TRL is the right choice when evaluating the product and the aspects of technology. In the desired use of "liquid wood" in the construction industry, the TRL scale does not represent all the challenges of integrating a given technology into a system. Thus, the scale may certainly be refined. The roadmap is a "first-cut" one and made to "get the job done". The roadmap is simple in nature and robust in structure. The roadmap is good for starting, keeping track, and successfully ending a project but not sufficiently complex and detailed to keep track of all project parameters. For example, the need to closely monitor and control "liquid wood" injection parameters (a problem of technological fine-tuning) is revealed in a practical way via trial and error as the development progresses. This challenge is not present in the roadmap.

A study by Tomaschek et al. (2016) has identified four priority challenges when improving the use of TRL: Representation of integration between technologies, interface maturity, modifications in the system, and overall system maturity. Some of these literature findings are in line with the TRL use on the "liquid wood". Modifications in the overall system and the overall system maturity of the "liquid wood" are certainly not encompassed by the TRL scale and revealed in a practical manner. For instance, adjustments in the overall system, such as in the apparatus for the injection of the "liquid wood", are made after the initial experimentation. Likewise, the overall maturity of the system can only be evaluated after the "liquid wood" injection apparatus is proven to work. Thus, the overall system maturity can be discussed by looking back on the work done. However, not all challenges listed by the abovementioned literature are encountered because the TRL use is in line with the original requirements that NASA once requires and does not considerably differ from their original formulation.

In the case of the "liquid wood", the TRL helps when associated with a timeline (the $O X$ axis of the roadmap). Thus, the laboratory work, technical testing, and work meetings can easily be planned around the TRL levels in a well-defined time span. Holmes and Campbell Jr (2004) ascertain that using TRL can substantially cut down the build-test-fix product cycles. Moreover, the TRL is useful in keeping track of the "liquid wood" project as it progresses because different project stages are equated to TRL levels, resulting in clearly defined thresholds that should be reached. Clausing and Fey (2004) argue that the TRL is an important component of new product innovation, which is indeed the case for the "liquid wood".

Second, roadmapping is proven useful in illustrating the advancement of the "liquid wood" from a semiexperimental material to a construction industry rehabilitation solution. The literature provides examples on how the roadmapping helps bring various products on the market or their development in accordance with market expectations. Martin and Eggink (2008) propose a graphical roadmap for thermal technology in consumer electronics. Daim and Intarode (2011) create a roadmap for the future use of cement in the construction industry. An effective and comprehensive roadmap is created using the Fast Start T-Process proposed by Phaal et al. (2003). In terms of content, the roadmap is grafted on the requirements of the "liquid wood" project. Thus, a customized form is obtained. Perhaps the biggest advantage lies in the graphical nature of the roadmap, which allows for the relevant illustration of the key steps and decisions concerning the "liquid wood" project. Graphically depicting the roadmap follows the recommendations of Phaal 
et al. (2004b). Also, the roadmap layers, showing the perspectives of the "liquid wood" material development (product, technology, and market), are clearly laid out as Phaal and Muller (2009) suggest.

Third, the TRL and the roadmapping are generally known well in the scientific literature but as separate concepts. The TRL-oriented roadmap is obtained by combining these concepts. Several examples of TRLoriented roadmaps are presented (Palaszewski et al., 2010; Ruehl and Bull, 2012; Sabharwall et al., 2012). The roadmap is graphically defined, and a breakdown of what it is and how it functions is introduced. This breakdown corresponds to the actual work done to raise the TRL level. The TRL levels can be viewed as operating instructions and how one should use and understand the "liquid wood" roadmap.

\subsection{Construction industry interviews}

The Rogers' characteristics of innovation (found in the Diffusion of Innovation Theory), i.e., relative advantage, compatibility, complexity, trialability, and observability, are used in designing interview questions. These characteristics are inserted in the interview questions to be pertinent when seeking answers from the interviewees. Annex A presents the breakdown on how each interview question embeds the Rogers' characteristics of innovation.

Looking at the "liquid wood" through an innovative perspective (at least from a material point of view), this product may fulfill most of the innovation criteria to a large degree and should encounter little effort in its adoption and diffusion in the construction industry. The adoption of the "liquid wood" in the construction industry is hindered by other factors. Following this line of argument, an interesting parallel can be drawn between the adoption of new materials in the construction industry and the adoption of the information and communications technology (ICT) in the US healthcare system. Christensen and Remler (2009) show that the reason why ICT does not find their way in the healthcare system is related to high replacement costs and the need for technical compatibility, which results in technological lock-in on already adopted technologies. The "liquid wood", which is already twice as expensive as regular plastics, costs a substantial amount to replace conventional building materials, and the technical compatibility means designing all necessary tools, processes, and regulations that will make biomaterials a viable alternative.

Interviews reveal that the real problems of adoption concerning the "liquid wood" do not necessarily lie in costs and technology issues. By contrast, interviewees acknowledge and appreciate the innovative potential of the material, and the problems associated with cost and technology and their main concerns are tied to the lack of government incentives and adequate adoption legislation. A particular criticism is the lengthy and intricate certification process that each new material has to pass before it is available for use by the construction industry.

Linking to the answers provided by the interviewees, the available literature suggests that government incentives and the promotion of new legislation can help new materials reach the market, and decreased pollution can be a major factor when talking about the product adoption. A survey by Arora et al. (2014) on the adoption of nanomaterials in the construction industry has found that the government does little on regulation and legislation when dealing with such products. Another survey by Tam et al. (2007) reveals that when dealing with implementing prefabrication techniques in the construction industry, which help mitigate pollution, the government only declaratively supports such initiative but does not enforce them actively. Moreover, Gan et al. (2015) states that government policies and regulations provide the main path to limiting the negative effect of the construction industry on the environment and the society. Finally, a paper by Dewick and Miozzo (2002) on the use of innovative and eco-friendly insulation materials in buildings throughout the UK has found that the other hindrances in adopting said materials are conservatism in the construction industry, lack of information about eco-friendly alternatives, and high cost. Their article concludes that without the help of government regulation, innovative materials will not succeed on their own in countering the problems posed by climate change and sustainability.

Notably, interviews are taken in the construction sector of Romania, which has a conservative and bureaucratically laden industry compared with its Western European counterparts (Frâncu, 2015). This finding may be because of profound societal changes after 1989 (Carey, 2004). Therefore, in the author's point of view, the construction sector in Romania presents a big challenge to the adoption of the "liquid wood".

Overall, the Romanian construction industry seems receptive to modern building materials in the past years. The main issue is that relevant government authorities are still looked upon with distrust and sometimes even contempt because they are portrayed as being closeminded and incapable of appreciating the novelty factor and other advantages that new materials in the construction industry possess.

\subsection{Validity of findings}

The use of the TRL and the roadmap is discussed in the context of the "liquid wood". The TRL and the roadmapping are successfully applied before on various products and processes. On roadmapping, Ghobakhloo (2018) discusses the strategic roadmap for the Industry 4.0 Initiative. Silventoinen et al. (2009) present a roadmap for the life cycle product management in small- and mediumsize enterprises (SMEs). Kelly-Cirino et al. (2019) analyze an updated roadmap for MERS-CoV research and product 
development. In the case of TRL, Hicks et al. (2009) propose a methodology for evaluating the TRL during product development. Rybicka et al. (2016) assess the TRL level of composite recycling technologies. Thus, the generality of the TRL and the roadmapping is already proven in several domains.

Considering the previous discussion subchapters, supporting literature shows that the concepts of TRL, roadmapping, and the TRL-oriented roadmapping represent valuable planning and tracking tools, which can be customized and adapted to a variety of products and processes in diverse fields. Moreover, these concepts may be used in various circumstances pertaining to the construction industry. For example, the roadmapping can be used in the management of typically large projects (e.g., hospitals, monuments, and water dams) where the integration of construction team specialties is crucial to the success of such endeavors. The TRL can play a role in tracking construction industry technologies and developing new tools and machinery (e.g., a new model of power drill). The flexibility and the adaptability of these instruments validate them as suitable choices for studying the development path of the "liquid wood".

The interview's results concerning the "liquid wood" are consistent with further literature findings. Most interviewees stress the importance of government regulation and policy, which are both related to the possible adoption of the "liquid wood" and other biocomposite products. Pollution mitigation and high costs aside, the government is a major driver in the adoption and the use of such materials by the industry. Interview results gain weight and significance when viewed in the literature context.

\section{Conclusions}

This paper aims to follow the development of a roadmap on the development, adoption, and diffusion of a biocomposite product, i.e., the "liquid wood", for use in the construction industry.

This paper has found that the TRL and the roadmapping are relevant tools for the development of a product. Despite its age, the TRL remains viable in planning the proper steps of product development. The roadmapping is also useful in mapping out the said steps. When applied on a sectoral level, the roadmapping remains relevant. The TRL-oriented roadmapping, which combines two tools, has yielded meaningful results in terms of product planning and development. Finally, the interviews are useful as a method for garnering knowledge "from the source" about the adoption and the diffusion of the "liquid wood" as a construction industry product.

This paper has some limitations. First, interviews are made by considering a relatively small pool of interviewees. A large number of interviewees is desirable to obtain an accurate opinion. Second, interviews are only carried out in the Romanian construction industry due to previously stated reasons. However, the whole "liquid wood" picture will be complete and possibly clear if interviews are carried in multiple countries and can indicate a fertile ground for the timely adoption and diffusion of "liquid wood" and biocomposite products.

The investigation of other possible uses of the "liquid wood" and other biocomposite/bio-based products in the construction industry (structural or otherwise) is suggested. Research in this area is lacking, and a big black hole of unknown data results in the late adoption of such materials, thereby resulting in negative consequences for the environment.

Studying the adoption of these novel materials (or materials considered novel due to the period in which they have appeared) is also suggested. Differences exist in the construction industry's views between Western and Eastern Europe. One view is perceived as innovative and modern, and the other view is perceived as conservative and traditional. Studying whether the ponderous adoption and diffusion of novel products is a result of the remnant pre-1989 construction philosophies or the post-1989 transition to an open market and a free economy, which is recognized as difficult in many Eastern European countries, will be interesting.

Another research direction is to carry out a case study on the effectivity of the actual roadmapping when applied on a sectoral level. Authors analyze the development of a roadmap that stems from a perceived necessity or challenge (development of the "liquid wood" as a product for the construction industry). The said roadmap is developed by considering a practical perspective and represents a singular case of roadmap use. Comparing such examples and seeing what lessons can be obtained, is suggested.

This paper scientifically provides a largely nontechnical perspective on the development and the possible usage of the "liquid wood" and biocomposites in the construction industry. The marketing pillar of the TRL-oriented roadmap, which contains adoption- and diffusion-themed interviews, is important in revealing possible measures to promote the emergence and the use of such materials in the construction industry.

Business implications may be far-reaching as, for the adoption of such materials in the construction sector, it is reasonable to presume that changes will probably have to take place throughout many of the construction industry's branches. Construction processes change, and tools and procedures for the use of biocomposites must be devised. The workforce should be trained and acclimatized with these products. Legislation should accommodate this new class of building materials.

The studies presented throughout this paper can be appropriate to other species of biocomposite materials if they are also starting in the laboratory and ending on the shelves of construction material vendors. Thus, the 
TRL-oriented roadmapping approach may be used as a model on how such products can be developed for use in a certain industry. Technological and marketing approaches may vary in accordance with specific material requirements.

In conclusion, the "liquid wood" may have potential as a material in the construction industry, and its eventual adoption may be notably delayed or hampered by the lack of support from governments and other relevant authorities. Although perceived as traditional and conservative, the construction industry is curious about these materials. If the environmental aspect comes into play with an eye towards the foreseeable future, delaying the adoption and the diffusion of biocomposites and green materials in the construction industry will result in environmental consequences.

\section{Annex A - Interview structure}

\section{Introductory questions:}

1. Are you working in the construction industry?/Have you ever worked before in the construction industry?

2. What is/was your qualification?

3. What is/was your field of expertise?

4. Have you ever heard about biocomposites before? (if not, explain what they are)

5. Have you ever heard about "liquid wood"? (if not, explain what "liquid wood" is)

\section{Product questions:}

1. Are you interested in "liquid wood" as a material for structural applications, non-structural or both?

2. Can you think about any applications regarding "liquid wood" in the construction industry? (explain beforehand where "liquid wood" was already employed)

3. If the product were to prove its qualities in the real world, would you consider it a serious, long-term alternative to more classic products? (relative advantage)

4. If more "liquid wood" blends were to be available (with different properties), would it benefit you in any way? (explain what blends are available now and what blend of "liquid wood" is currently explored for use in the construction industry) (trialability)

5. Do you have knowledge of any other high-performance products that can be used for the same purpose as "liquid wood"? (compatibility)

6. Do you have knowledge of any other high-performance products that can be used for the same purpose, such as "liquid wood" but also adhere to the "bio" principles? (compatibility)

\section{Technology questions:}

7. Given the structural properties of "liquid wood", do you believe it can be employed, in a structural role, by the construction industry? (explain beforehand mechanical properties of "liquid wood") (relative advantage)

8. Can you see this product being used on the construction site? (trialability)

9. Do you think more testing is needed for the product, or the quantity of available data is enough? (briefly list properties of "liquid wood" studies) (trialability)

10. Would you like us to perform any other type of test on "liquid wood"? (trialability)

11. "Workability" is a qualitative property of building materials. Can you estimate how "workable" would "liquid wood" be considered on the construction site? (relative advantage)

12. How extensive do you think workforce training should be regarding the employment of "liquid wood" on the construction site? (briefly explain the intended operating procedure \& necessary tools) (complexity)

13. Would you think the above-explained operating procedure is easy to understand and use? (explain in-situ behavior similar to epoxy resins) (compatibility)

14. Would other methods of employing "liquid wood" be more desirable than the one currently being researched? (complexity)

\section{Marketing (adoption) questions:}

15. If you had a deciding role in an organization, would you employ "liquid wood" in a building project? (observability)

16. What actors in the construction industry do you think might be interested in finding out more about this biocomposite? (observability)

17. Is it desirable to find "liquid wood" as a product "offthe-shelf" at construction material vendors or would ordering it online suffice?

18. What legal issues (regarding certification, Occupational Health and Safety (OHS), etc.) would you foresee regarding "liquid wood", before becoming adopted as a viable construction material?

19. Would you use "liquid wood" as a standalone building material, if it became more affordable? (explain that $25 \mathrm{~kg}$ of "liquid wood" = 400 Euros) (trialability)

20. Do you believe a separate company should exist in the construction industry specializing in "liquid wood" in which you could subcontract when required, or should construction companies be dedicated in understanding, adopting and making use of this material? (complexity)

21. Do you see any future use for "liquid wood" in the construction industry? (observability)

Note: Please answer all questions in a "WHY" manner! (justify your answers)

\section{References}

Arora S K, Foley R W, Youtie J, Shapira P, Wiek A (2014). Drivers of technology adoption-The case of nanomaterials in building 
construction. Technological Forecasting and Social Change, 87: 232244

Carey H F (2004). Romania Since 1989: Politics, Economics, and Society. Lanham: Lexington Books

Christensen M C, Remler D (2009). Information and communications technology in US health care: Why is adoption so slow and is slower better? Journal of Health Politics, Policy and Law, 34(6): 1011-1034

Clausing D, Holmes M (2010). Technology readiness. Research Technology Management, 53(4): 52-59

Clausing D P, Fey V (2004). Effective Innovation: The Development of Winning Technologies. New York: ASME Press

Cornford S L, Sarsfield L (2004). Quantitative methods for maturing and infusing advanced spacecraft technology. In: IEEE Aerospace Conference. Big Sky, MT

Daim T U, Intarode N (2011). Technology roadmapping for mature industries: 2010-2050 global cement product roadmap. International Journal of Technology, Policy and Management, 11(2): 173-186

Dewick P, Miozzo M (2002). Sustainable technologies and the innovation-regulation paradox. Futures, 34(9-10): 823-840

Eindhoven T U (2016). The world's first biocomposite bridge on the TU/e campus. Available at: tue.nl/en/news/news-overview/24-102016

Environmental Pollution Centers (2017). Construction sites pollution. Available at: environmentalpollutioncenters.org/construction/

European Space Agency (ESA) (2008). Technology Readiness Levels Handbook for Space Applications. ESA Document TEC-SHS/5551/ $\mathrm{MG} / \mathrm{ap}$

Faruk O, Bledzki A, Fink H, Sain M (2012). Biocomposites reinforced with natural fibers: 2000-2010. Progress in Polymer Science, 37(11): $1552-1596$

Frâncu L G (2015). The impact of bureaucracy over the foreign direct investments in Romania. Theoretical and Applied Economics, 22 (Special(I)): 33-38

Gan X, Zuo J, Ye K, Skitmore M, Xiong B (2015). Why sustainable construction? Why not? An owner's perspective. Habitat International, 47: 61-68

Garcia M L, Bray O H (1997). Fundamentals of technology roadmapping. Sandia Report. Albuquerque, NM: Sandia National Laboratories

Ghobakhloo M (2018). The future of manufacturing industry: A strategic roadmap toward Industry 4.0. Journal of Manufacturing Technology Management, 29(6): 910-936

Goodman L A (1961). Snowball sampling. Annals of Mathematical Statistics, 32(1): 148-170

Groenveld P (1997). Roadmapping integrates business and technology. Research Technology Management, 40(5): 48-55

Hicks B, Larsson A, Culley S J, Larsson T (2009). A methodology for evaluating technology readiness during product development. In: Proceedings of the 17th International Conference on Engineering Design. Stanford, CA, 3: 157-168

Holmes M F, Campbell Jr R B (2004). Product development processes: Three vectors of improvement. Research Technology Management, 47(4): 47-55

John M J, Thomas S (2008). Biofibres and biocomposites. Carbohydrate Polymers, 71(3): 343-364

Kelly-Cirino C, Mazzola L T, Chua A, Oxenford C J, van Kerkhove M D
(2019). An updated roadmap for MERS-CoV research and product development: Focus on diagnostics. BMJ Global Health, 4: e001105

Lay T, Kanamori H, Ammon C J, Nettles M, Ward S N, Aster R C, Beck S L, Bilek S L, Brudzinski M R, Butler R, DeShon H R, Ekström G, Satake K, Sipkin S (2005). The great Sumatra-Andaman earthquake of 26 December 2004. Science, 308(5725): 1127-1133

Lee J H, Phaal R, Lee S H (2013). An integrated service-devicetechnology roadmap for smart city development. Technological Forecasting and Social Change, 80(2): 286-306

Mankins J (2009). Technology readiness assessments: A retrospective. Acta Astronautica, 65(9-10): 1216-1223

Martin G, Eggink E (2008). Creation of a thermal technology roadmap in a consumer electronics product environment. In: IEEE/CPMT 24th Semiconductor Thermal Measurement, Modeling \& Management Symposium, 106-111

Mihály H (2017). From NASA to EU: The evolution of the TRL scale in public sector innovation. The Innovation Journal, 22(2): 3

Nägele H, Pfitzer J, Eyerer P, Eisenreich N, Elsner P, Eckl W (2004). Composite body with decorative layers. European Patent 1135441B1

Nägele H, Pfitzer J, Ziegler L, Inone-Krauffmann E R, Eckl W, Eisenreich N (2014). Lignin matrix composites from natural resources-ARBOFORM ${ }^{\circledR}$. In: Kabasci S, ed. Bio-Based Plastics: Materials and Applications. Hoboken, NJ: John Wiley \& Sons Ltd., 89-115

National Aeronautics and Space Administration (NASA) (2014). Technology readiness levels (TRL). Available at: nasa.gov/directorates/heo/scan/engineering/technology

Nedelcu D, Ciofu C, Lohan N (2013). Microindentation and differential scanning calorimetry of "liquid wood". Composites Part B: Engineering, 55: 11-15

Nedelcu D, Plavanescu S, Puiu E (2014). Impact resistance of "liquid wood". Advanced Materials Research, 1036: 13-17

Nedelcu D, Stefan A, Mindru T, Plavanescu S (2012). Flexural properties of samples obtained from "liquid wood". Selected Engineering Problems, 3: 151-154

Ortiz O, Castells F, Sonnemann G (2009). Sustainability in the construction industry: A review of recent developments based on LCA. Construction \& Building Materials, 23(1): 28-39

Palaszewski B A, Goebel D, White H, Coote D (2010). DRAFT InSpace Propulsion Systems Roadmap. Technology Area 02. National Aeronautics and Space Administration

Petrick I, Echols A (2004). Technology roadmapping in review: A tool for making sustainable new product development decisions. Technological Forecasting and Social Change, 71(1-2): 81-100

Phaal R, Farrukh C, Mitchell R, Probert D (2003). Starting-up roadmapping fast. Research Technology Management, 46(2): 52-59

Phaal R, Farrukh C, Probert D (2004a). Customizing roadmapping. Research Technology Management, 47(2): 26-37

Phaal R, Farrukh C, Probert D (2004b). Technology roadmapping-A planning framework for evolution and revolution. Technological Forecasting and Social Change, 71(1-2): 5-26

Phaal R, Muller G (2009). An architectural framework for roadmapping: Towards visual strategy. Technological Forecasting and Social Change, 76(1): 39-49

Probert D, Radnor M (2016). Frontier experiences from industry-academia consortia. Research-Technology Management, 46(2): 27-30 
Puiu E, Văideanu D, Simona B E, Agop M (2017). Thermal and electrical behaviors of the Arbofill "liquid wood". International Journal of Modern Manufacturing Technologies, 4(1): 79-83

Purcaru G (1979). The Vrancea, Romania earthquake of March 4, 1977 - a quite successful prediction. Physics of the Earth and Planetary Interiors, 18(4): 274-287

Rödel J, Kounga A B N, Weissenberger-Eibl M, Koch D, Bierwisch A, Rossner W, Hoffmann M J, Danzer R, Schneider G (2009). Development of a roadmap for advanced ceramics: 2010-2025. Journal of the European Ceramic Society, 29(9): 1549-1560

Rogers E M (2003). Diffusion of Innovations. 5th ed. New York: Free Press

Ruehl K, Bull D (2012). Wave energy development roadmap: Design to commercialization. In: 2012 Oceans. Hampton Roads, VA, 1-10

Rybicka J, Tiwari A, Leeke G A (2016). Technology readiness level assessment of composites recycling technologies. Journal of Cleaner Production, 112: 1001-1012

Sabharwall P, McCllar M, Siahpush A, Clark D, Patterson M, Collins J (2012). Technology development roadmap for the advanced high temperature reactor secondary heat exchanger. Technical Report. Idaho Falls, ID: Idaho National Laboratory

Sadin S, Povinelli F, Rosen R (1989). The NASA technology push towards future space mission systems. Acta Astronautica, 20: 73-77 Schinasi K V (1999). Best practices: Better management of technology development can improve weapon system outcomes. Chapter Report NSIAD-99-162. Washington: General Accounting Office

Siebelink R (2013). The Road Ahead: Business Roadmapping and How to Compensate for Uncertainty-The Case of the Construction Company. Dissertation for the Master's Degree. Enschede: University of Twente

Silventoinen A, Papinniemi J, Lampela H (2009). A roadmap for product lifecycle management implementation in SMEs. In: The 10th ISPIM Conference, 21

Sykes L R, Jaumé S C (1990). Seismic activity on neighbouring faults as a long-term precursor to large earthquakes in the San Francisco Bay area. Nature, 348(6302): 595-599

Tam V W Y, Tam C M, Zeng S X, Ng W C Y (2007). Towards adoption of prefabrication in construction. Building and Environment, 42(10): 3642-3654

Tecnaro GmbH (2020). TECNARO - The Biopolymer Company| Applications. Available at: tecnaro.de/en/anwendungen/

Tomaschek K, Olechowski A, Eppinger S, Joglekar N (2016). A survey of technology readiness level users. In: INCOSE International Symposium, 26(1): 2101-2117

Vos J (2018). Demonstrating biocomposites' properties using BioBridges. Available at: allthings.bio

Willyard C, McClees C (1987). Motorola's technology roadmap process. Research Management, 30(5): 13-19 